Original article

Perinatology Vol. 30, No. 1, March, 2019

https://doi.org/10.14734/PN.2019.30.1.1

\title{
The Incidence and Survival Rate of Very Low Birth Weight Infants in Korea (2013- 2016): A Comparison of the Statistics Korea and the Korean Neonatal Network and Im- provements
}

Jisu Kim, MD',

Hye-Eun Kim, MD',

Kyung-Suk Lee, MD',

Sung-Hoon Chung, MD',

Yong-Sung Choi, MD',

Chong-Woo Bae, MD',

Korean Neonatal Network

${ }^{1}$ Department of Pediatrics, Kyung Hee University School of Medicine, Seoul; ${ }^{2}$ Department of Pediatrics, CHA Bundang Medical Center, CHA University, Seongnam, Korea

Received: 20 July 2018

Revised: 22 August 2018

Accepted: 27 September 2018

Correspondence to

Sung-Hoon Chung, MD

Department of Pediatrics, Kyung Hee University Hospital, 23 Kyungheedaero, Dongdaemoon-gu, Seoul 02447, Korea

Tel: +82-2-440-6287

Fax: $+82-2-440-7175$

E-mail: pedc@hanmail.net

Copyright@ 2019 by The Korean Society of Perinatology

This is an Open Access article distributed under the terms of the Creative Commons Attribution Non-Commercial License (http://creativecommons.org/ license/by-nc/4.0/), which permits unrestricted non-commercial use, distribution, and reproduction in any medium, provided that the original work is properly cited.
Objective: We aimed to compare the total number of live births and survival rates of very low birth weight infants (VLBWIs) from the Statistics Korea and the Korean Neonatal Network (KNN) data between 2013 and 2016, and to find out the direction in which the total number of VLBWIs is included in KNN.

Methods: We obtained the number of live births and deaths of VLBWIs and extremely low birth weight infants among vital statistics of the Statistics Korea from 2013 to 2016 and compared the differences with KNN data using the KNN annual reports during the same period.

Results: The survival rates were $84.2 \%, 86.5 \%, 84.9 \%$ for VLBWIs in the Statistics Korea, and 83.4\%, $86.4 \%, 84.6 \%$ in the KNN data from 2014 to 2016. There was no significant difference between the data. The rates of registration of VLBWIs (registration number of the KNN/registration number of the Statistics Korea) showed 50.8\%, 87.7\%, 87.7\%, 88.3\% between 2013 and 2016, respectively. It showed an increasing trend every year. However, registration rates according to the birth weight (BW) and gestational age (GA) were significantly lower in BW of less than $400 \mathrm{~g}$ and $\mathrm{GA}$ of less than 22 weeks.

Conclusion: KNN is considered to be a good database representing the number of births of VLBWIs born in Korea. However, it is necessary to establish the GA of survival limits in the data of the Statistics Korea, and acquire data on the number of VLBWIs who are not collected by hospitals and clinics in Korea.

Key Words: Very low birth weight infants, Live birth, Survival rate, Vital statistics

\section{서론}

임신과 출산과정 그리고 영유아 건강관리를 지원하기 위한 정책을 수립할 때 이 항목들에 대한 정확한 정보를 확보하는 것이 필수적이며, 이것은 인구정책을 위한 가장 기본적인 요 건이 된다. 대부분의 선진국에서 모든 신생아가 출생 후 국가시스템에 등록되며, 의학적으 로 지정된 사망 원인으로 사망할 때도 기록으로 남게 된다. ${ }^{1,2}$ 한국 통계청도 출생에 대한 여 러 통계 자료를 제시하고 있으며, 출생 체중 $1,500 \mathrm{~g}$ 미만의 극소저체중출생아(very low birth weight infants, VLBWIs)의 출생과 사망 수를 2005년부터 발표하기 시작하여 2009년 부터는 매년 제시하고 있다.

현재 한국에서는 점점 낮아지는 출산율에도 불구하고 조산아 및 VLBWIs가 차지하는 비 중이 현저히 증가하고 있다. 통계청 자료에 따르면 한국의 총 출생 수는 1996년에 691,226명 에서 2016년에 406,243명으로 20년 만에 약 40\% 감소한 반면 VLBWIs 수는 1996년에 1,205 명에서 2016년에 2,783명으로 $230 \%$ 증가하였고 총 출생아 중 VLBWIs의 비율은 $0.17 \%$ 에서 $0.69 \%$ 로 증가하여 $406 \%$ 의 증가를 나타냈다. ${ }^{3}$ 여러 의학 기술과 신생아 중환자 
치료의 발달로 고위험 신생아의 생존율이 현저하게 향상되었으 나 아직 선진국에 비해서는 약간 낮은 편이다. 각 병원 신생아 중환자실마다 생존율도 다양하게 나타나며, 합병증 또한 편차 가 큰 실정이어서 국내의 전국 VLBWIs를 등록하고 관리하기 위한 데이터베이스의 필요성이 대두되었다. ${ }^{4,5}$ 이러한 필요성에 따라 2013년 4월에 한국신생아네트워크(Korean Neonatal Network, KNN)가 발족되어 전국 신생아 중환자실에 입원하는 VLBWIs의 등록, 자료 분석, 질병 이환율 및 사망률 등을 매년 보고하고 있고 2018년 현재 71개의 병원이 참여하고 있다. ${ }^{6}$

본 연구는 2013년부터 2016년까지 한국 통계청과 $\mathrm{KNN}$ 의 자 료에서 VLBWIs의 출생 수와 생존율을 비교하여 현재 $\mathrm{KNN}$ 의 등록현황을 파악하고, 전국적으로 모든 VLBWIs 출생 수가 포 함될 수 있는 방법 및 개선 사항을 모색하고자 하였다.

\section{대상 및 방법}

2013년부터 KNN이 시작되어 매년 연차보고서를 발표하고 있다. 이 연차보고서에는 $\mathrm{KNN}$ 에 등록된 신생아 중환자실에서 해당 연도에 보고된 VLBWIs의 각종 자료를 취합하여 보고서를 발행하고 있는데, 보고서의 중요 항목으로 eligibility evaluation $\&$ demographic, 임신 분만, 신생아 정보 등이 있다. 이 중 퇴원 관련 정보 속에 VLBWIs의 사망률 항목이 출생 체중, 임신 기간 별로 구분 정리된 것이 있다. 출생 체중은 $100 \mathrm{~g}$ 단위별로 <400 $\mathrm{g}$ 에서 1,400-1,499 g까지 구분되어 있고, 임신 기간은 20주 또 는 21 주에서 36 또는 38 주까지 1주 간격으로 분류되어 있다. 본 연구에서는 2013년, ${ }^{7} 2014$ 년, ${ }^{8} 2015$ 년, ${ }^{9} 2016$ 년도 ${ }^{10} \mathrm{KNN}$ 보고 서를 바탕으로 하였다.

또한, 2013년 1월부터 2016년 12월까지 통계청 자료 중에서 VLBWIs, 초극소저체중출생아(extremely low birthweight infants, ELBWIs)의 출생 수와 사망 수를 확보하고 같은 기간 $\mathrm{KNN}$ 연차보고서와 발표된 논문들을 참조하여 두 자료 간 차이를 비교 하였다. 통계청 자료 출생 수에서 미상 값은 제외하였고, 출생 수 와 사망 수를 토대로 두 자료 간 출생 체중별 그리고 임신 기간별 등록률 및 생존율을 비교하였다. 출생 체중은 $400 \mathrm{~g}$ 미만, 400499 g, 500-599 g, 600-699 g, 700-799 g, 800-899 g, 900999 g, 1,000-1,099 g, 1,100-1,199 g, 1,200-1,299 g, 1,300$1,399 \mathrm{~g}, 1,400-1,499 \mathrm{~g}$ 으로 구분하였고 임신 기간은 22 주에서 37 주까지 1 주 간격으로 나타내었고 22 주 미만과 37 주 이상은 각 각 하나의 그룹으로 나누었다. 등록률( $\mathrm{KNN}$ 등록 수/통계청 등록 수)은 통계청 등록 수에 대한 $\mathrm{KNN}$ 의 등록 수를 나타낸 것으로 정의하였다. $\mathrm{KNN}$ 연차보고서에서의 사망은 출생 후부터 신생
아 중환자실 퇴원 전까지의 사망을 의미하며, 통계청 출생 통계 에서의 사망은 생후 28 일 이내의 사망을 의미한다.

통계프로그램은 SPSS version 21.0 (SPSS Inc., Chicago, IL, $\mathrm{USA}$ )을 이용하였고, 통계청 및 $\mathrm{KNN}$ 자료에 기술된 생존율의 비교에는 Pearson's Chi-squared test를 사용하였다. $P$-value 가 0.05 미만인 경우를 통계적으로 유의하다고 판단하였다.

Table 1. Total Number of Birth and Percentage on VLBWls and ELBWIs in Korea (2013-2016)

\begin{tabular}{lccc}
\hline Year & No. of births & VLBWIs & ELBWIs \\
\hline 2013 & 436,455 & $2,961(0.68)$ & $1,144(0.26)$ \\
2014 & 435,435 & $2,870(0.66)$ & $1,119(0.26)$ \\
2015 & 438,420 & $3,031(0.69)$ & $1,133(0.26)$ \\
2016 & 406,243 & $2,781(0.68)$ & $1,030(0.25)$ \\
\hline
\end{tabular}

Values are presented as number (\%).

These data quoted from Bae and Chung $^{3}$ with permission.

Abbreviations: No., number; VLBWIs, very low birth weight infants; ELBWIs, extremely low birth weight infants.

Table 2. The Number and Percentage of Neonatal Deaths in Korea* (2013-2016)

\begin{tabular}{cccc}
\hline Year & No. of neonatal deaths & VLBWIs & ELBWIs \\
\hline 2013 & 752 & $434(57.7)$ & $350(46.5)$ \\
2014 & 743 & $454(61.1)$ & $365(49.1)$ \\
2015 & 677 & $409(60.4)$ & $337(50.5)$ \\
2016 & 660 & $419(63.5)$ & $351(53.2)$ \\
\hline
\end{tabular}

Values are presented as number (\%).

These data quoted from Bae and Chung $^{3}$ with permission.

Abbreviations: No., number; VLBWls, very low birth weight infants; ELBWIs, extremely low birth weight infants.

*Death within 28 days after birth.

Table 3. Differences in Registration Number between the Statistics Korea and the KNN and Registration Rate (2013-2016)

\begin{tabular}{cccccc}
\hline \multirow{6}{*}{ VLBWIs } & Year & $\begin{array}{c}\text { Statistics Korea } \\
\text { No. of births (A) }\end{array}$ & $\begin{array}{c}\text { KNN* }^{*} \\
\text { No. of births (B) }\end{array}$ & $\begin{array}{c}\text { Differences } \\
(\mathrm{B}-\mathrm{A})\end{array}$ & $\begin{array}{c}\text { B/A } \\
(\%)\end{array}$ \\
\hline \multirow{6}{*}{ ELBWIs } & 2013 & 2,961 & 1,502 & $-1,459$ & 50.7 \\
& 2014 & 2,870 & 2,128 & -353 & 87.7 \\
& 2015 & 3,031 & 2,657 & -374 & 87.7 \\
& 2016 & 2,781 & 2,457 & -324 & 88.3 \\
& 2013 & 1,144 & 589 & -555 & 51.5 \\
& 2015 & 1,119 & 980 & -139 & 87.6 \\
& 2016 & 1,133 & 985 & -148 & 86.9 \\
\hline
\end{tabular}

These data quoted from Bae and Chung ${ }^{3}$ and The Executive Committee of Korean Neonatal Network ${ }^{7-10}$ with permission.

Abbreviations: KNN, Korean Neonatal Network; No., number; VLBWIs, very low birth weight infants; ELBWIs, extremely low birth weight infants.

*Include unregistered cases. 


\section{결과}

통계청 자료에 의하면 2013년에서부터 2016년까지의 각 연 도별 총 출생아 대비 VLBWIs의 출생 비율은 0.66-0.69\%로 모 두 $1 \%$ 미만으로 비슷하게 나타났고 ELBWIs의 출생 비율은 2013년도부터 2015년까지 0.26\%로 동일하였으며 2016년에 도 $0.25 \%$ 로 비슷하게 나타났다(Table 1). 또한 통계청에서 발

Table 4. Comparison of the Number of Births and the Survival Rates on VLBWIs and ELBWIs between the Statistics Korea and the KNN (2014-2016)

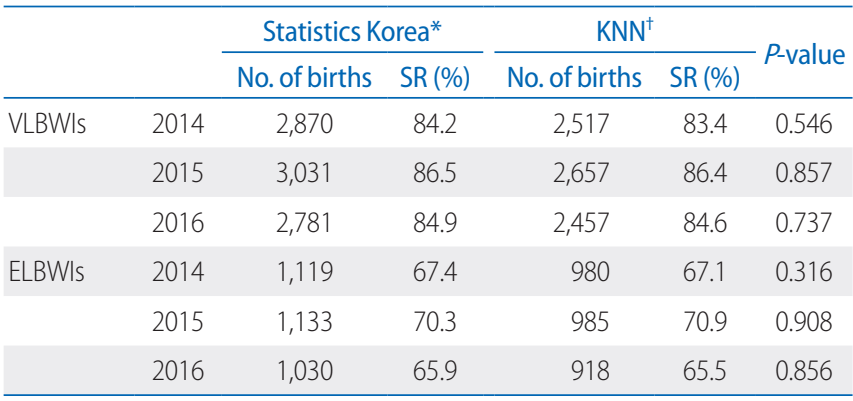

These data quoted from The Executive Committee of Korean Neonatal Network ${ }^{8-10}$ with permission.

Abbreviations: VLBWIs, very low birth weight infants; ELBWIs, extremely low birth weight infants; KNN, Korean Neonatal Network; No., number; SR, survival rates.

*Death within 28 days after birth.

†Include unregistered cases.
표한 한국 신생아 사망 수(생후 28일 이내 사망)는 2013년에는 752명, 2016년에는 660명으로 년도가 지날수록 점점 감소하는 경향을 보이고 있으나 신생아 사망 수에서 VLBWIs와 ELBWIs 가 차지하는 비율은 2016년으로 갈수록 점점 증가하는 경향을 볼 수 있었다(Table 2).

2013년 통계청에서 발표한 VLBWIs의 등록 수와 KNN에서 발 표한 등록 수의 차이는 $\mathrm{KNN}$ 이 처음 발족된 시기인 2013년은 시 범 기간으로 참여 병원이 적어 $\mathrm{KNN}$ 이 통계청에 비하여 1,459 명 더 적었고, 2014년에는 353명이 적었으며 2015년에는 374명으 로 두 기관의 등록 수 차이가 2014년도와 비슷하게 나타났고 2016년에는 324명으로 두 기관의 차이가 가장 적게 나타났다. ELBWIs의 등록 수 차이 또한 2013년에는 559명, 2016년에는 112 명으로 두 기관의 등록 수 차이는 년도가 지날수록 점점 더 적어지고 있다. 따라서 통계청 등록 수에 대한 $\mathrm{KNN}$ 의 등록 수 를 나타낸 등록률(KNN 등록 수/통계청 등록 수)도 VLBWIs와 ELBWIs 모두 년도가 지날수록 점점 증가하여 2016년에는 각 각 $88.3 \%$ 와 $89.0 \%$ 를 나타냈다(Table 3 ).

시범사업 기간이었던 2013년을 제외하고 VLBWIs의 생존율 은 2014년에서부터 2016년까지 KNN 자료에서 83.4\%,86.4\%, $84.6 \%$, 통계청 자료는 $84.2 \%, 86.5 \%, 84.9 \%$ 로 두 기관이 비슷 하였고, 2014년에서부터 2016년까지 ELBWIs의 경우에서도 비슷한 수치를 보였다(Table 4). 출생 체중별로 2014년에서부

Table 5. Comparison of the Survival Rates between the Statistics Korea and the KNN by birth weight (2014-2016)

\begin{tabular}{|c|c|c|c|c|c|c|c|c|c|c|c|c|}
\hline \multirow{3}{*}{$\begin{array}{l}\text { Birth } \\
\text { weight } \\
\text { group (g) }\end{array}$} & \multicolumn{4}{|c|}{2014} & \multicolumn{4}{|c|}{2015} & \multicolumn{4}{|c|}{2016} \\
\hline & \multicolumn{2}{|c|}{ Statistics Korea* } & \multicolumn{2}{|r|}{$\mathrm{KNN}^{\dagger}$} & \multicolumn{2}{|c|}{ Statistics Korea* } & \multicolumn{2}{|r|}{$\mathrm{KNN}^{+}$} & \multicolumn{2}{|c|}{ Statistics Korea* } & \multicolumn{2}{|r|}{$\mathrm{KNN}^{\dagger}$} \\
\hline & $\begin{array}{l}\text { No. of } \\
\text { births }\end{array}$ & $\begin{array}{c}\text { Survival } \\
\text { No. (SR* [\%]) }\end{array}$ & $\begin{array}{l}\text { No. of } \\
\text { births }\end{array}$ & $\begin{array}{c}\text { Survival } \\
\text { No. (SR* }[\%])\end{array}$ & $\begin{array}{l}\text { No. of } \\
\text { births }\end{array}$ & $\begin{array}{c}\text { Survival } \\
\text { No. }\left(\mathrm{SR}^{*}[\%]\right)\end{array}$ & $\begin{array}{l}\text { No. of } \\
\text { births }^{\dagger}\end{array}$ & $\begin{array}{c}\text { Survival } \\
\text { No. (SR* [\%]) }\end{array}$ & $\begin{array}{l}\text { No. of } \\
\text { births }\end{array}$ & $\begin{array}{c}\text { Survival } \\
\text { No. (SR* [\%]) }\end{array}$ & $\begin{array}{l}\text { No. of } \\
\text { births }^{\dagger}\end{array}$ & $\begin{array}{c}\text { Survival } \\
\text { No. (SR* [\%]) }\end{array}$ \\
\hline$<400$ & 31 & $3(9.7)$ & 15 & $2(13.3)$ & 45 & $2(4.4)$ & 12 & $1(8.3)$ & 30 & $2(6.7)$ & 13 & $0(0.0)$ \\
\hline 400-499 & 61 & $21(34.4)$ & 44 & $18(40.9)$ & 70 & $19(27.1)$ & 54 & $17(31.5)$ & 69 & $12(17.4)$ & 47 & $11(23.4)$ \\
\hline 500-599 & 135 & $53(39.3)$ & 118 & $51(43.2)$ & 116 & $50(43.1)$ & 99 & $39(39.4)$ & 108 & $52(48.1)$ & 89 & $38(42.7)$ \\
\hline 600-699 & 172 & $99(57.6)$ & 155 & $86(55.5)$ & 184 & $109(59.2)$ & 159 & $97(61.0)$ & 176 & $97(55.1)$ & 156 & $83(53.2)$ \\
\hline 700-799 & 200 & $141(70.5)$ & 187 & $122(65.2)$ & 210 & $160(76.2)$ & 190 & $136(71.6)$ & 196 & $134(68.4)$ & 181 & $115(63.5)$ \\
\hline 800-899 & 235 & $189(80.4)$ & 205 & $165(80.5)$ & 245 & $214(87.3)$ & 224 & $177(79.0)$ & 212 & $174(82.1)$ & 205 & $160(78.0)$ \\
\hline 900-999 & 285 & $248(87.0)$ & 256 & $214(83.6)$ & 263 & $242(92.0)$ & 247 & $231(93.5)$ & 239 & $208(87.0)$ & 227 & $194(85.5)$ \\
\hline $1,000-1,099$ & 280 & 262 (93.6) & 256 & $230(89.8)$ & 301 & 277 (92.0) & 263 & $238(90.5)$ & 262 & 235 (89.7) & 216 & $190(88.0)$ \\
\hline $1,100-1,199$ & 280 & $263(93.9)$ & 237 & $219(92.4)$ & 335 & $322(96.1)$ & 314 & $296(94.3)$ & 296 & $282(95.3)$ & 264 & $252(95.5)$ \\
\hline 1,200-1,299 & 333 & 315 (94.6) & 299 & 276 (92.3) & 394 & $383(97.2)$ & 349 & 336 (96.3) & 340 & 336 (98.8) & 314 & $308(98.1)$ \\
\hline 1,300-1,399 & 402 & $384(95.5)$ & 353 & $339(96.0)$ & 374 & 363 (97.1) & 318 & 310 (97.5) & 401 & $387(96.5)$ & 351 & $342(97.4)$ \\
\hline $1,400-1,499$ & 456 & 438 (96.1) & 392 & $378(96.4)$ & 494 & $481(97.4)$ & 428 & $418(97.7)$ & 452 & $443(98.0)$ & 394 & 385 (97.7) \\
\hline Total & 2,870 & $2,416(84.2)$ & 2,517 & $2,100(83.4)$ & 3,031 & $2,622(86.5)$ & 2,657 & 2,296 (86.4) & 2,781 & $2,362(84.9)$ & 2,457 & 2,078 (84.6) \\
\hline
\end{tabular}

These data quoted from Bae and Chung ${ }^{3}$ and The Executive Committee of Korean Neonatal Network ${ }^{8-10}$ with permission.

Abbreviations: KNN, Korean Neonatal Network; No., number; SR, survival rates.

*Death within 28 days after birth.

${ }^{\dagger}$ Include unregistered cases. 
터 2016년도까지의 통계청과 $\mathrm{KNN}$ 의 생존율 비교에서도 통계 학적으로 의미 있는 차이는 보이지 않았고, 임신 기간별로 비교 를 하였을 때 22주 미만에서 통계청의 생존율은 2014년에 $7.7 \%, 2015$ 년에 0\%, 2016년에 6.3\%를 나타냈으나 $\mathrm{KNN}$ 자료 에서의 생존율은 2014년에 20\%, 그 후 2년 동안 모두 $0 \%$ 를 나 타냈고 22 주 미만 이외의 임신 기간에서는 두 기관에서 통계학 적으로 의미 있는 차이가 없었다(Tables 5, 6).

2014년에서부터 2016년까지의 출생 체중별 통계청과 KNN 의 등록률을 비교 정리해 보면 2014, 2015, 2016년 출생 체중 $400 \mathrm{~g}$ 미만에서의 등록률이 $48.4 \%, 26.7 \%, 43.3 \%$ 로 최소를 나 타냈으며 출생 체중 그룹 전체적인 등록률은 2014년에 87.7\%, 2015년에 87.6\%, 2016년에 88.3\%로 2014년도와 2015년도는 비슷하였고 2016년에 가장 높게 나타났다(Table 7). 3년간 (2014-2016년) 출생 체중 $400 \mathrm{~g}$ 미만의 평균 등록률이 $37.7 \%$ 로 기타 출생 체중에 비하여 많이 떨어져 있는 양상을 보였다 (Fig. 1). 임신 기간별 등록률에서는 2014, 2015, 2016년 22주 미만에서 각각 $38.5,19.0,21.9 \%$ 로 최소를 나타냈으며(Table
8) 3년 동안(2014-2016년) 22주 미만 출생아에서 다른 주수에 비하여 평균 등록률이 현저히 낮았다(Fig. 2).

\section{고찰}

1980년대부터 많은 국가들이 조산아 관련 네트워크를 만들 어 지역별 자원을 공유하고, 효과적인 신생아 진료체계를 구축 해오고 있다; Vermont Oxford Network, Australian and New Zealand Neonatal Network, Canadian Neonatal Network, Israel Neonatal Network, Neonatal Research Network of Japan, Spanish Neonatal Network, Swedish Neonatal Quality Register, Swiss Neonatal Network, and United Kingdom Neonatal Collaborative. 여기에 등록된 신생아들의 신생아 중 환자실 자료와 외래 추적관찰 자료들은 신생아 중환자실의 질 향상, 다기관 조산아 임상연구 활성화뿐만 아니라 국가의 보건 의료 정책방안에도 도움을 주고 있다. ${ }^{11,12}$ 한국에서는 대한신생

Table 6. Comparison of the Survival rates between the Statistics Korea and the KNN by pregnancy period (2014-2016)

\begin{tabular}{|c|c|c|c|c|c|c|c|c|c|c|c|c|}
\hline \multirow{3}{*}{$\begin{array}{l}\text { Pregnancy } \\
\text { period } \\
\text { group } \\
\text { (weeks) }\end{array}$} & \multicolumn{4}{|c|}{2014} & \multicolumn{4}{|c|}{2015} & \multicolumn{4}{|c|}{2016} \\
\hline & \multicolumn{2}{|c|}{ Statistics Korea* } & \multicolumn{2}{|r|}{$\mathrm{KNN}^{\dagger}$} & \multicolumn{2}{|c|}{ Statistics Korea* } & \multicolumn{2}{|r|}{$\mathrm{KNN}^{+}$} & \multicolumn{2}{|c|}{ Statistics Korea* } & \multicolumn{2}{|r|}{$\mathrm{KNN}^{+}$} \\
\hline & $\begin{array}{l}\text { No. of } \\
\text { births }\end{array}$ & $\begin{array}{c}\text { Survival } \\
\text { No. }\left(\mathrm{SR}^{*}[\%]\right) \\
\end{array}$ & $\begin{array}{l}\text { No. of } \\
\text { births }\end{array}$ & $\begin{array}{c}\text { Survival } \\
\text { No. }\left(\mathrm{SR}^{*}[\%]\right)\end{array}$ & $\begin{array}{l}\text { No. of } \\
\text { births }\end{array}$ & $\begin{array}{c}\text { Survival } \\
\text { No. }\left(\mathrm{SR}^{*}[\%]\right) \\
\end{array}$ & $\begin{array}{l}\text { No. of } \\
\text { births }\end{array}$ & $\begin{array}{c}\text { Survival } \\
\text { No. }\left(\mathrm{SR}^{*}[\%]\right)\end{array}$ & $\begin{array}{l}\text { No. of } \\
\text { births }\end{array}$ & $\begin{array}{c}\text { Survival } \\
\text { No. }\left(\mathrm{SR}^{*}[\%]\right) \\
\end{array}$ & $\begin{array}{l}\text { No. of } \\
\text { births }\end{array}$ & $\begin{array}{c}\text { Survival } \\
\text { No. (SR* [\%]) }\end{array}$ \\
\hline$<22$ & 26 & $2(7.7)$ & 10 & $2(20.0)$ & 42 & $0(0.0)$ & 8 & $0(0.0)$ & 32 & $2(6.3)$ & 7 & $0(0.0)$ \\
\hline 22 & 35 & $3(8.6)$ & 25 & $2(8.0)$ & 43 & $11(25.6)$ & 30 & $4(13.3)$ & 45 & $7(15.6)$ & 28 & $5(17.9)$ \\
\hline 23 & 118 & $33(28.0)$ & 96 & 35 (36.5) & 113 & $33(29.2)$ & 90 & 35 (38.9) & 91 & 36 (39.6) & 75 & $27(36.0)$ \\
\hline 25 & 219 & $164(74.9)$ & 207 & $154(74.4)$ & 239 & $183(76.6)$ & 235 & $172(73.2)$ & 185 & $116(62.7)$ & 175 & $102(58.3)$ \\
\hline 26 & 273 & $217(79.5)$ & 245 & 175 (71.4) & 267 & $221(82.8)$ & 250 & $202(80.8)$ & 229 & $185(80.8)$ & 224 & $170(75.9)$ \\
\hline 27 & 279 & $250(89.6)$ & 263 & $226(85.9)$ & 311 & $278(89.4)$ & 294 & $257(87.4)$ & 267 & $237(88.8)$ & 246 & $213(86.6)$ \\
\hline 28 & 353 & $322(91.2)$ & 321 & $292(91.0)$ & 404 & 380 (94.1) & 359 & 336 (93.6) & 354 & $330(93.2)$ & 306 & $283(92.5)$ \\
\hline 32 & 169 & $164(97.0)$ & 146 & $142(97.3)$ & 158 & 154 (97.5) & 135 & 134 (99.3) & 164 & 160 (97.6) & 154 & $149(96.8)$ \\
\hline 33 & 111 & $110(99.1)$ & 96 & $95(99.0)$ & 136 & $134(98.5$ & 124 & $123(99.2)$ & 113 & $108(95.6)$ & 91 & 87 (95.6) \\
\hline 34 & 101 & $98(97.0)$ & 80 & 79 (98.8) & 104 & 101 (97.1) & 88 & 85 (96.6) & 95 & 93 (97.9) & 74 & 73 (98.6) \\
\hline 35 & 45 & 44 (97.8) & 40 & 38 (95.0) & 56 & $54(96.4)$ & 53 & $51(96.2)$ & 51 & 49 (96.1) & 43 & $43(100.0)$ \\
\hline 36 & 34 & $29(85.3)$ & 21 & $21(100.0)$ & 27 & 27 (100) & 20 & $20(100.0)$ & 33 & 30 (90.9) & 23 & $23(100.0)$ \\
\hline$\geq 37$ & 12 & 11 (91.7) & 10 & $10(100.0)$ & 18 & 15 (83.3) & 9 & $7(77.8)$ & 17 & $10(58.8)$ & 6 & $6(100.0)$ \\
\hline Total & 2,870 & $2,416(84.2)$ & 2,516 & 2,099 (83.4) & 3,031 & ,2622 (86.5) & 2,657 & 2,296 (86.4) & 2,781 & 2,362 (84.9) & 2,457 & 2,078 (84.6) \\
\hline
\end{tabular}

These data quoted from Bae and Chung $^{3}$ and The Executive Committee of Korean Neonatal Network ${ }^{8-10}$ with permission. Abbreviations: KNN, Korean Neonatal Network; No., number; SR, survival rates. *Death within 28 days after birth.

${ }^{\dagger}$ Include unregistered cases. 
Table 7. Comparison of the Number of Births and Registration Rate between the Statistics Korea and the KNN by Birth Weight (2014-2016)

\begin{tabular}{|c|c|c|c|c|c|c|c|c|c|}
\hline \multirow{2}{*}{$\begin{array}{l}\text { Birth weight } \\
\text { group (g) }\end{array}$} & \multicolumn{3}{|c|}{2014} & \multicolumn{3}{|c|}{2015} & \multicolumn{3}{|c|}{2016} \\
\hline & Statistics Korea (A) & $\mathrm{KNN}^{*}(\mathrm{~B})$ & $\mathrm{B} / \mathrm{A}(\%)$ & Statistics Korea (C) & $\mathrm{KNN}^{*}(\mathrm{D})$ & C/D (\%) & Statistics Korea (E) & $\mathrm{KNN}^{*}(\mathrm{~F})$ & $E / F(\%)$ \\
\hline$<400$ & 31 & 15 & 48.4 & 45 & 12 & 26.7 & 30 & 13 & 43.3 \\
\hline 400-499 & 61 & 44 & 72.1 & 70 & 54 & 77.1 & 69 & 47 & 68.1 \\
\hline 500-599 & 135 & 118 & 87.4 & 116 & 99 & 85.3 & 108 & 89 & 82.4 \\
\hline 600-699 & 172 & 155 & 90.1 & 184 & 159 & 86.4 & 176 & 156 & 88.6 \\
\hline 700-799 & 200 & 187 & 93.5 & 210 & 190 & 90 & 196 & 181 & 92.3 \\
\hline 800-899 & 235 & 205 & 87.2 & 245 & 224 & 91.4 & 212 & 205 & 96.7 \\
\hline 900-999 & 285 & 256 & 89.8 & 263 & 247 & 93.9 & 239 & 227 & 95 \\
\hline $1,000-1,099$ & 280 & 256 & 91.4 & 301 & 263 & 87.4 & 262 & 216 & 82.4 \\
\hline 1,100-1,199 & 280 & 237 & 84.6 & 335 & 314 & 93.7 & 296 & 264 & 89.2 \\
\hline $1,200-1,299$ & 333 & 299 & 89.8 & 394 & 349 & 88.6 & 340 & 314 & 92.4 \\
\hline $1,300-1,399$ & 402 & 353 & 87.8 & 374 & 318 & 85 & 401 & 351 & 87.5 \\
\hline $1,400-1,499$ & 456 & 392 & 86.0 & 494 & 428 & 86.6 & 452 & 394 & 87.2 \\
\hline Total & 2,870 & 2,517 & 87.7 & 3,031 & 2,657 & 87.6 & 2,781 & 2,457 & 88.3 \\
\hline
\end{tabular}

These data quoted from Bae and Chung ${ }^{3}$ and The Executive Committee of Korean Neonatal Network ${ }^{8-10}$ with permission. Abbreviation: KNN, Korean Neonatal Network.

*Include unregistered cases.

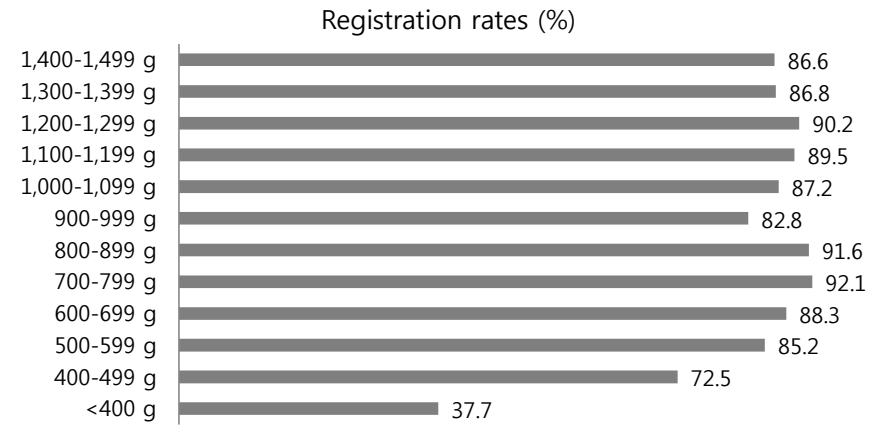

Fig. 1. Average registration rates (registration number of the KNN/registration number of the Statistics Korea [\%]) by birth weight (grams) (2014-2016). These data quoted from Bae and Chung ${ }^{3}$ and The Executive Committee of Korean Neonatal Network ${ }^{8-10}$ with permission. KNN, Korean Neonatal Network.

아학회가 주관하고 한국 질병관리본부가 협력하는 $\mathrm{KNN}$ 이 2013년에 설립되었다. ${ }^{6}$ 2018년 7월 현재 국내 전체 신생아 중 환자실 중 71 개가 참여하고 총 11,900 여 명의 VLBWIs 등록이 진행 중에 있으며, 매년 $\mathrm{KNN}$ 에서 연차보고서를 발표, 배포하고 있다. ${ }^{7-10}$ 이 연차보고서를 바탕으로 한국 전체 신생아 통계를 보 여주는 통계청과 $\mathrm{KNN}$ 에 등록된 VLBWIs의 생존율을 비교해 보았을 때 한국 통계청이 생존율 계산에 생후 28 일 이내의 사망 을 사용하는데 반하여 $\mathrm{KNN}$ 에서는 신생아 중환자실 퇴원 전까 지의 사망을 사용하였지만 전체적인 생존율이 통계학적으로 의 미 있는 차이는 없었으며, 출생 체중별 및 임신 기간별 분류를 포함한 전체적인 생존율이 통계학적으로 의미 있는 차이를 보
이지 않았다. 이는 VLBWIs가 사망하는 경우 대부분 생후 4 주 이내에 사망하기 때문인 것으로 생각된다. ${ }^{13}$ 한국 통계청과 $\mathrm{KNN}$ 등록 수를 비교해 보았을 때 약간의 차이가 있었지만, VLBWIs의 등록률은 2014년 87.7\%에서 2016년 88.3\%로 증가 하였으며, ELBWIs도 $87.6 \%$ 에서 $89.1 \%$ 로 증가하였다. 대표성 있는 표본(representative sample)이란 모집단 전체를 잘 대표 하는 표본이라는 의미이며, 표본의 규모가 어느 이상 커야 하고, 비교 기준이 동일해야 한다. ${ }^{14}$ 하지만 $90 \%$ 가까운 등록률을 보 인다는 점에서 표본조사보다는 거의 전수조사에 가깝기 때문에 $\mathrm{KNN}$ 자료에 표본의 대표성을 따지는 것 자체가 무의미할 것이 다.

2016년도 통계청 자료를 보면, VLBWIs 총 사망 수 419명 중 ELBWIs가 351명(83.8\%)으로 대부분을 차지하였고(Table 2) 이 중 출생 체중 $500 \mathrm{~g}$ 미만 출생아 99명 중 사망 수가 85명 (20.3\%), 임신 기간 22주 미만 사망 수가 30명(7.2\%)으로 VLBWIs의 생존율 하락에 큰 영향을 주고 있었다(Tables 5, 6). 하지만 통계청 자료와 비교하여 $\mathrm{KNN}$ 의 임신 기간 22 주 미만 출 생 수와 출생 체중 $400 \mathrm{~g}$ 미만 출생 수가 다른 임신 기간 및 출생 체중에 비해서 차이가 크게 나타났다. 이는 통계청 자료 수집에 있어 생존한계를 넘는 임신 기간 21주 미만 아기들도 출생시 사 산만 아니면 통계에 포함되기 때문에 VLBWIs의 출생 수가 실제 보다 많게 발표되는 경향이 있고 이는 다소 무리가 있어 보여 통 계청 자료에서 생존한계 주수의 확립이 필요할 것으로 생각된 다. 또한 VLBWIs 대부분은 병원의 신생아 중환자실에 입원하 
Table 8. Comparison of the Number of Births and Registration Rate between the Statistics Korea and the KNN by Pregnancy Period (2014-2016)

\begin{tabular}{|c|c|c|c|c|c|c|c|c|c|}
\hline \multirow{2}{*}{$\begin{array}{r}\text { Gestational age } \\
\text { group (weeks) }\end{array}$} & \multicolumn{3}{|c|}{2014} & \multicolumn{3}{|c|}{2015} & \multicolumn{3}{|c|}{2016} \\
\hline & Statistics Korea (A) & $\mathrm{KNN}^{*}(\mathrm{~B})$ & $\mathrm{B} / \mathrm{A}(\%)$ & Statistics Korea $(\mathrm{C})$ & $\mathrm{KNN}^{*}(\mathrm{D})$ & $\mathrm{C} / \mathrm{D}(\%)$ & Statistics Korea (E) & $\mathrm{KNN}^{*}(\mathrm{~F})$ & $E / F(\%)$ \\
\hline$<22$ & 26 & 10 & 38.5 & 42 & 8 & 19.0 & 32 & 7 & 21.9 \\
\hline 22 & 35 & 25 & 71.4 & 43 & 30 & 69.8 & 45 & 28 & 62.2 \\
\hline 23 & 118 & 96 & 81.4 & 113 & 90 & 79.6 & 91 & 75 & 82.4 \\
\hline 24 & 169 & 154 & 91.1 & 156 & 132 & 84.6 & 169 & 159 & 94.1 \\
\hline 25 & 219 & 207 & 94.5 & 239 & 235 & 98.3 & 185 & 175 & 94.6 \\
\hline 26 & 273 & 245 & 89.7 & 267 & 250 & 93.6 & 229 & 224 & 97.8 \\
\hline 27 & 279 & 263 & 94.3 & 311 & 294 & 94.5 & 267 & 246 & 92.1 \\
\hline 28 & 353 & 321 & 90.9 & 404 & 359 & 88.9 & 354 & 306 & 86.4 \\
\hline 29 & 370 & 314 & 84.9 & 386 & 354 & 91.7 & 382 & 344 & 90.1 \\
\hline 30 & 320 & 260 & 81.3 & 347 & 284 & 81.8 & 310 & 285 & 91.9 \\
\hline 31 & 236 & 228 & 96.6 & 224 & 192 & 85.7 & 244 & 217 & 88.9 \\
\hline 32 & 169 & 146 & 86.4 & 158 & 135 & 85.4 & 164 & 154 & 93.9 \\
\hline 33 & 111 & 96 & 86.5 & 136 & 124 & 91.2 & 113 & 91 & 80.5 \\
\hline 34 & 101 & 80 & 79.2 & 104 & 88 & 84.6 & 95 & 74 & 77.9 \\
\hline 35 & 45 & 40 & 88.9 & 56 & 53 & 94.6 & 51 & 43 & 84.3 \\
\hline 36 & 34 & 21 & 61.8 & 27 & 20 & 74.1 & 33 & 23 & 69.7 \\
\hline$\geq 37$ & 12 & 10 & 83.3 & 18 & 9 & 50.0 & 17 & 6 & 35.3 \\
\hline Total & 2,870 & 2,516 & 87.7 & 3,031 & 2,657 & 87.7 & 2,781 & 2,457 & 88.3 \\
\hline
\end{tabular}

These data quoted from Bae and Chung ${ }^{3}$ and The Executive Committee of Korean Neonatal Network ${ }^{8-10}$ with permission. Abbreviation: KNN, Korean Neonatal Network.

*Include unregistered cases.

\section{Registration rates(\%)}

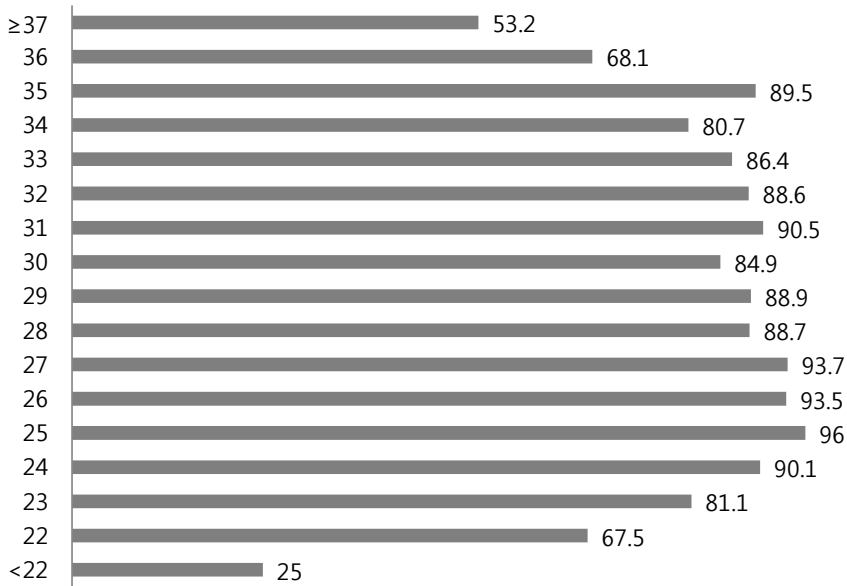

Fig. 2. Average registration rates (registration number of the KNN/registration number of the Statistics Korea [\%]) by pregnancy period (weeks) (2014-2016). These data quoted from Bae and Chung ${ }^{3}$ and The Executive Committee of Korean Neonatal Network ${ }^{8-10}$ with permission. KNN, Korean Neonatal Network.

게 되며 병원에서 사망하게 되는 경우 '사망원인보안조사'를 위 하여 병원 내의 모자보건신고를 담당하는 부서(주로 의무기록
실)에서 신고를 하게 되어 있는데, 이 자료가 미비하여 출생 체 중이나 임신 기간이 공란인 경우가 많다. 이런 경우 통계청에서 출생 체중이 공란일 경우 임신 기간을 참고하여 출생 체중의 추 정치를 자료에 넣고, 임신 기간이 공란일 경우는 출생 체중을 참 고하여 임신 기간의 추정치를 자료에 넣고 있어 $\mathrm{KNN}$ 자료와 어 느 정도 차이가 생길 수 밖에 없을 것으로 생각된다.

또한 한국 통계청 자료에 미상이 많았다. 출생 신고 시에 인구 동향조사라는 것을 같이 하도록 되어 있는데 인구동향조사에는 출생 신고서에는 없는 신생아의 임신 기간, 출생 체중, 다태아 여부 및 출생 순위 등이 포함된다. 인구동향조사는 보호자가 원 하지 않는 경우에 하지 않을 수 있으므로 보호자에 의하여 인구 동향조사에 참여하지 않게 되는 신생아는 정보가 부족하므로 출생 수에서 미상에 포함되게 된다. ${ }^{15}$ 사망 신고는 사망 사실을 안 날부터 한 달 이내에 동거하는 친족이 사망자의 등록기준지 또는 신고자의 주소지의 시, 구, 읍, 면의 사무소나 매장지, 화장 지에서 시행하게 되어 있다. 보통 사망 신고는 세 가지 방법을 통하여 이루어지는데 앞서 말한 동거하는 친족이 하는 사망 신 고가 구축을 이루고 화장장에서의 신고가 있으며 세 번째로는 앞서 말한 의료기관에서 하는 사망원인보안조사라는 것을 통하 
여 사망 신고가 이루어지고 이 세 가지 자료는 중복될 수 있다. 사망자의 출생 신고가 안 되어 있을 경우에는 출생 신고와 사망 신고를 동시에 시행하게 되어 있으나 이러한 경우 출생 신고 및 사망 신고를 안 하는 경우가 적지 않아서 1999년부터 매년 2회 각 시도로부터 화장장의 영유아 사망처리자료를 수집하고 있고 수집된 자료를 출생 및 사망 신고 자료와 대조하여 누락 자료를 보완하고 있다. 이 경우 자료가 미비하여 많은 경우가 미상에 포 함되게 된다. ${ }^{16}$

KNN이 발족된 2013년에 총 49개, 2015년에 60개, ${ }^{6}$ 2017년 에는 69개의 병원 Neonatal Intensive Care Unit이 KNN에 참 여하였고, ${ }^{15}$ 2018년 현재에는 71 개가 참여하고 있으며 앞으로 더 증가할 것으로 예상된다. 한국 통계청 자료에 비하여 현재의 $\mathrm{KNN}$ 자료만으로도 한국 VLBWIs 출생 수를 대표하는 훌륭한 자료이며 객관적인 피드백을 통한 각 병원의 발전과 $\mathrm{KNN}$ 데이 터를 활용한 활발한 다기관 연구를 기대할 만하다. 궁극적으로 $\mathrm{KNN}$ 자료가 한국의 VLBWIs 전체 출생 수를 표현하는 데이터 베이스로의 접근이 필요하고 이를 위해서는 $\mathrm{KNN}$ 의 역할과 장 점을 잘 홍보하여 $\mathrm{KNN}$ 에 아직 가입하지 않은 신생아 중환자실 의 참여 독려가 필요하다. 기타 병·의원 자료에 잡히지 않는 한 국의 VLBWIs 출생 수에 대한 자료 확보 방안도 필요할 것으로 생각된다.

한국의 $\mathrm{KNN}$ 을 기반으로 우선 인근 아시아 지역에서 한국보 다 일찍 신생아 네트워크를 구축하여 운영 중인 국가들과 정보 교류를 통해서 국제화의 기반을 마련하고, 우리의 시스템을 보 완하며, 나아가 현재 9개국이 참여해 있는 International Network for Evaluating Outcomes of Neonates의 데이터베이스에 참여 하는 것도 국제적으로 향상할 수 있는 좋은 기회가 될 것이 다. ${ }^{11,12}$

\section{Acknowledgments}

This study was carried out with support from the Korea Centers for Disease Control and Prevention (2016-ER630700\#).

\section{References}

1) Henderson ZT, Suchdev DB, Abe K, Johnston EO, Callaghan WM. Perinatal quality collaboratives: improving care for mothers and infants. J Womens Health (Larchmt) 2014;23:368-72.

2) Mikkelsen L, Phillips DE, AbouZahr C, Setel PW, de Savigny D, Lozano R, et al. A global assessment of civil registration and vital statistics systems: monitoring data quality and progress. Lancet 2015;386:1395-406.

3) Bae CW, Chung SH. Maternal and infant health statistics in Korea. 1st ed. Seoul: Medical Hub, 2018.

4) Shim JW, Kim MJ, Kim EK, Park HK, Song ES, Lee SM, et al. The impact of neonatal care resources on regional variation in neonatal mortality among very low birthweight infants in Korea. Paediatr Perinat Epidemiol 2013;27:216-25.

5) Choi CW, Kim BI, Kim EK, Song ES, Lee JJ. Incidence of bronchopulmonary dysplasia in Korea. J Korean Med Sci 2012;27:914-21.

6) Chang YS, Park HY, ParkWS. The Korean Neonatal Network: an overview. J Korean Med Sci 2015;30 Suppl 1:S3-11.

7) The Executive Committee of Korean Neonatal Network. 2013 Korean Neonatal Network annual report. Cheongju: Korean Centers for Disease Control and Prevention, 2014

8) The Executive Committee of Korean Neonatal Network. 2014 Korean Neonatal Network annual report. Cheongju: Korean Centers for Disease Control and Prevention, 2015.

9) The Executive Committee of Korean Neonatal Network. 2015 Korean Neonatal Network annual report. Cheongju: Korean Centers for Disease Control and Prevention, 2016.

10) The Executive Committee of Korean Neonatal Network. 2016 Korean Neonatal Network annual report. Cheongju: Korean Centers for Disease Control and Prevention, 2017.

11) Shah PS, Lee SK, Lui K, Sjörs G, Mori R, Reichman B, et al. The International Network for Evaluating Outcomes of very low birth weight, very preterm neonates (iNeo): a protocol for collaborative comparisons of international health services for quality improvement in neonatal care. BMC Pediatr 2014;14:110

12) Shah PS, Lui K, Sjörs G, Mirea L, Reichman B, Adams M, et al. Neonatal outcomes of very low birth weight and very preterm neonates: an international comparison. J Pediatr 2016;177:144-52.e6.

13) Lim JW, Chung SH, Kang DR, Kim CR. Risk factors for cause-specific mortality of very-low-birth-weight infants in the Korean Neonatal Network. J Korean Med Sci 2015;30 Suppl:S35-44.

14) Kandola D, Banner D, O'Keefe-McCarthy S, Jassal D. Sampling methods in cardiovascular nursing research: an overview. Can J Cardiovasc Nurs 2014;24:15-8.

15) Chung SH, Bae CW. Improvement in the survival rates of very low birth weight infants after the establishment of the Korean Neonatal Network: comparison between the 2000s and 2010s. J Korean Med Sci 2017;32: 1228-34.

16) Statistics Korea. Annual report on live births and deaths statistics (based on vital registration). Daejeon: Statistics Korea, 2017. 